and by other enzymatic, endocrine, metabolic and behavioural idiosyncrasies. By contrast, goldthioglucose mice, which exemplify 'regulatory' obesity, namely, that type of obesity in which the hyperphagia is due exclusively to a lesion in the higher nervous centres controlling appetite, have normal levels of serum cholesterol. Regulatory forms of obesity are characterized by the fact that rates of lipogenesis and cholesterologenesis are brought back to normal levels when hyperphagia is eliminated and by the fact that body composition goes back to normal when weight is reduced to control levels.

The cholesterol picture of the yellow mice parallels the more complex sex-linked situation observed in these animals ${ }^{6}$ : the female mice, which are characterized by much greater adiposity and rates of lipogenesis and cholesterologenesis higher than normal when fasted (unpublished work) are also character. ized by high levels of cholesterol.

It thus appears that obese mice of different types suitably compared may offer particularly good material for the study of factors influencing the concentration of serum cholesterol and for the study of the influence of this on the development of lesions of atherosclerosis.

This work was supported in part by the National Institute of Arthritis and Metabolism (grant No. $A-49)$; the Nutrition Foundation, New York; and the Fund for Research and Teaching Department of Nutrition, Harvard.

$$
\text { Claire Zomzely* }
$$$$
\text { JEAN MAYeR }
$$

Department of Nutrition,

Harvard School of Public Health, Boston, Mass. Sept. 10.

* Predoctoral Research Fellow of the National Heart Institute. 1 Mayer, J., Nutr. Abst. and Rev., 25, 597 (1955).

2 Mayer, J., Metabolism, 5, 435 (1957).

${ }^{3}$ Abell, L. L., Levy, B. B., Brodie, B. B., and Kendall, F. E., J. Biol. Chem., 160, 31 (1953).

- Bates, M. W., Zomzely, C., and Mayer, J., Amer. J. Physiol., 181, $187(1955)$.

${ }^{5}$ Zomzely, C., and Mayer, J., Amer. J. Physiol., 187, 365 (1956). - Carpenter, K., and Mayer, J., Amer. J. Physiol., 193, 499 (1958).

\section{Toxicity of a Cholinesterase Inhibitor to the Hibernating Hamster}

METABoLIC activity is profoundly altered in the hibernating animal, as compared with that in the normal. Evidence is also available that under hibernating conditions nervous function in certain species can be affected ${ }^{1}$. Consequently it was of considerable interest to determine the toxicity of a ganglionic blocking agent to animals under the abnormal metabolic conditions produced by hiberna. tion. The toxicity of the cholinesterase inhibitor O,O-diethyl-S - 2 -diethylaminoethyl phosphonothiolate $^{2}$ has been determined in the nornal and hibernating hamster by the intraperitoneal route.

Hibernation was induced by keeping the animals in the cold. A group of one hundred male animals weighing between 100 and $130 \mathrm{gm}$., were kept in individual cages in the cold room. The temperature was adjusted to $+10^{\circ} \mathrm{C}$. for the first week, then lowered to $+5^{\circ} \mathrm{C}$. for the remainder of the experimental period. Animals were allowed $8 \mathrm{hr}$. of artificial light a day and disturbed as little as possible. Hibernation was induced in some animals as early as the sixth week and in others as late as the fifteenth week, by which time a total of forty animals had gone into hibernation. Inspection was carried out twice a day and toxicity determinations made $24 \mathrm{hr}$. after hibernation was first observed.

Handling of the animal, necessary for (intraperitoneal) injection, even if done with the greatest of care, initiates the waking mechanism, so that within a few hours the animal is active and apparently back to normal. Thus, strictly speaking, the results on toxicity refer to animals in the intermediate state between undisturbed hibernation and normal activity. Nevertheless, the rapid action of the inhibitor ensures that toxic symptoms are well established before a return to normal activity has been accomplished.

For each toxicity determination the inhibitor was made up afresh in anhydrous propylene glycol at a concentration of $1 \mathrm{~mm} \cdot{ }^{3} / \mathrm{ml}$, and an 'Agla' microsyringe was used for injection.

The LD50 determined on a normal group of 140 hamsters and calculated at the 5 per cent confidence limits by probit analysis was $0 \cdot 106+0 \cdot 006 \mathrm{~mm} .{ }^{3} / \mathrm{kgm}$. (intraperitoneal). The corresponding $L D 50$ for the hibernating group was $0.072 \pm 0.012 \mathrm{~mm} .^{3} / \mathrm{kgm}$. intraperitoneal.

The increased susceptibility of the hibernating group to the anticholinesterase is possibly a reflexion of the increased stress placed upon the animal by the cold environment or the metabolic readjustment necessitated by coming out of hibernation.

J. F. SCATFE

D. H. CAMPBel

Defence Research Kingston Laboratory,

Department of National Defence, P.O. Box 123,

Kingston, Ontario.

Oct. 2.

${ }^{1}$ Kayser, C., Anrée Biologique, 29, 109 (1953).

${ }^{2}$ Ghosh, R., and Newman, J. F., Chem. and Indust., 118 (1955).

\section{Rate of Absorption of Supplementary Free Amino-Acids during Digestion}

Anrmal feeding studies have demonstrated that utilization of dietary protein is improved when an amino-acid deficiency is corrected by supplementation with free amino-acid. This greater utilization of protein is detected by the greater gain in body-weight of the test animal per unit of protein eaten, or by an increase in the percentage of ingested nitrogen retained by the animal. The improvement of the nutritive value of bread ${ }^{1}$, rice ${ }^{2}$ and maize $e^{3}$ by supplementation with amino-acid has been demonstrated.

Although these investigations clearly point to nutritional improvement, supplementation of food proteins has been criticized on the grounds that the free amino-acids may be absorbed into the bloodstream before the amino-acids liberated by digestion of the protein. If this were so, the full value of the supplement would not be realized, since it has been demonstrated that efficient synthesis of tissue proteins occurs only when all the essential amino-acids are supplied simultaneously in the proper proportions ${ }^{4}$.

The experiments reported here were designed to compare the rate of absorption of a free amino-acid supplement with that of the amino-acids liberated by digestion of protein. Healthy mongrel dogs were fasted for an 18-hr. period before being fed a meal 